\title{
Tratamento da má oclusão de Classe II, divisão 1 de Angle, com protrusão maxilar utilizando-se recursos ortopédicos
}

\author{
Carla Maria Melleiro Gimenez*, André Pinheiro Bertoz*, Francisco Antonio Bertoz**
}

\begin{abstract}
Resumo
Objetivo: o presente trabalho tem o propósito de apresentar uma revisão da literatura acerca do tratamento da má oclusão de Classe II, divisão 1 de Angle, tendo a protrusão maxilar como o principal componente dessa má oclusão, durante a fase de crescimento e desenvolvimento craniofacial. Serão apresentadas as características de cada um desses aparelhos, os seus componentes, a forma adequada de utilização, os seus mecanismos de ação e, principalmente, os seus efeitos em todo o complexo dentofacial. Conclusão: nos casos em que se verifica apenas a protrusão maxilar, sem envolvimento mandibular, e se faz necessário o controle vertical, pode ser indicado o AEB, conjugado ao aparelho removível derivado do aparelho preconizado por Thurow. Já nas situações de combinação da protrusão maxilar com a retrusão mandibular, uma opção de tratamento é o ativador combinado à ancoragem extrabucal.
\end{abstract}

Palavras-chave: Má oclusão de Classe II. Divisão 1 de Angle. Ortopedia. Protrusão maxilar.

\section{INTRODUÇÃO}

O planejamento ortodôntico varia de acordo com a natureza da má oclusão, a qual resulta de um desequilíbrio entre as estruturas dentárias, esqueléticas e musculares. A má oclusão de Classe II, divisão 1 de Angle, apresenta diversas caracterizações, e a determinação do planejamento mais adequado deve ser em função do problema específico do paciente, com base em suas evidências clínicas e cefalométricas.

Diante de uma má oclusão com envolvimento esquelético, em pacientes que se apresentam em fase de crescimento, indica-se a utilização dos recursos ortopédicos como opção viável de aborda- gem precoce.

A utilização da ancoragem extrabucal como forma de tratamento dessa má oclusão tem sido amplamente relatada na literatura, demonstrando seus efeitos ortopédicos e ortodônticos, além da eficiência diretamente relacionada com o estágio de maturação do indivíduo, o gênero, a direção de crescimento das estruturas faciais e o vetor de força empregado (definido pela direção, duração e intensidade), além, é claro, do grau de cooperação e interesse do paciente.

A fase da dentadura mista, período em que o paciente encontra-se em franco crescimento e desenvolvimento, é muito favorável para o emprego

* Mestres e doutorandos em Ortodontia pela Faculdade de Odontologia de Araçatuba - UNESP.

** Professor Dr. do Departamento de Odontologia Infantil e Social da Faculdade de Odontologia de Araçatuba - UNESP. 
de aparelhos ortodônticos/ortopédicos, quando as possibilidades de intervenção são incontestáveis. A indicação correta da mecânica a ser empregada possibilita a obtenção de uma oclusão satisfatória e estável, com uma melhora do perfil facial. Dessa forma, muitas vezes, é possivel evitar extrações ou até mesmo o próprio tratamento ortodôntico corretivo, resultando na diminuição do tempo efetivo de tratamento.

Com a utilização dos recursos ortopédicos na correção das displasias ântero-posteriores das bases ósseas, existe a possibilidade de alterá-las espacial e morfologicamente, redirecionando o crescimento da maxila e liberando o potencial intrínseco de crescimento da mandíbula, gerando assim uma situação mais estável e equilibrada.

Os principais objetivos da intervenção ortodôntica/ortopédica residem no restabelecimento precoce de uma oclusão ideal, bem como no equilíbrio muscular e na harmonia facial, garantindo estabilidade. Este trabalho tem a proposta de abordar, por meio de uma revisão da literatura, as formas de tratamento da má oclusão de Classe II, divisão 1 de Angle, com protrusão maxilar utilizando-se recursos ortopédicos e suas peculiaridades.

\section{REVISÃO DA LITERATURA}

\section{A má oclusão de Classe II, divisão 1 de Angle}

A má oclusão de Classe II, divisão 1 de Angle, atinge a maior parte da população que procura tratamento ortodôntico, segundo Silva Filho, Freitas e Cavassan ${ }^{49}$, apresentando-se, em cerca de $40 \%$ da mesma, com etiologia multifatorial e, muitas vezes, associando-se a outros problemas, como a atresia de maxila e a mordida aberta.

$\mathrm{O}$ advento dos estudos cefalométricos, a partir da década de 30 , permitiu uma grande evolução dos conhecimentos sobre o crescimento e o desenvolvimento craniofacial e, conseqüentemente, a determinação da natureza da má oclusão de Classe II, divisão 1 de Angle; ou seja, se a deficiência localiza-se na maxila, na mandíbula, nas posições dentárias ou em combinações entre essas possibilidades.

Defendendo o conceito da má oclusão de Classe II, divisão 1 de Angle ${ }^{3}$, Brodie ${ }^{8}$ reafirmou que o primeiro molar superior constituía o ponto mais estável da dentadura, ocupando uma relação definida com a anatomia craniana. Por esta razão, a classificação das más oclusões baseava-se na posição assumida pela mandíbula e não pela maxila, sendo a Classe II definida pelo posicionamento distal do arco inferior. Durante muito tempo, a distoclusão dos molares inferiores era considerada uma deficiência do crescimento e/ou retroposição da mandíbula. Discordando dessa premissa, Anderson ${ }^{2}$ apresentou um trabalho em que discutiu diferentes casos clínicos e demonstrou que, em muitos deles, a mandíbula apresentava-se bem posicionada, com a maxila localizada anteriormente, criando uma aparente distoclusão dos molares inferiores e, conseqüentemente, exigindo modificações no plano de tratamento, o que admitia a necessidade de efeitos ortopédicos para a excelência de resultados nos tratamentos ortodônticos.

Estudando a localização das deficiências dessa má oclusão, Henry ${ }^{33}$ a subdividiu em quatro tipos: protrusão alveolar maxilar, protrusão basal maxilar, retrusão mandibular e micromandíbula.

A partir da década de 60, o papel da dimensão vertical foi finalmente reconhecido em razão, principalmente, das contribuições de Schudy ${ }^{48}$, que procurou mostrar a necessidade de avaliação tridimensional das más oclusões, de forma a ampliar a abordagem do paciente, facilitando sensivelmente o diagnóstico e direcionando adequadamente o planejamento clínico.

Voltado para a mesma linha de pesquisa e visando a classificação etiológica dos problemas dentoesqueléticos, Sassouni ${ }^{47}$ afirmou que a má oclusão de Classe II, divisão 1 de Angle, esquelética, resultaria de prognatismo maxilar, de um retrognatismo mandibular ou de ambos, quando sem alterações dimensionais. Notou ainda a ocorrência de um aumento no tamanho da maxila ou 
uma diminuição no tamanho da mandíbula e que essas alterações dimensionais e de posição podem ser encontradas em situações isoladas ou combinadas entre si.

Bass $^{4}$ verificou as alterações esqueléticas da maxila e da mandíbula, assim como as posições dentárias inadequadas, concluindo que esses fatores podem apresentar-se combinados, estabelecendo diferentes padrões da má oclusão de Classe II, divisão 1 de Angle, sejam eles dentários, esqueléticos ou dentoesqueléticos.

Moyers ${ }^{41}$ dividiu a má oclusão de Classe II, divisão 1 de Angle, apresentando-a com 6 possibilidades no sentido ântero-posterior e 5 no vertical, ou ainda a combinação das mesmas, o que permite um plano de tratamento durante a fase de crescimento que tenha como objetivo a restrição do crescimento ântero-posterior da maxila, ou a liberação do crescimento da mandíbula, ou ainda esses 2 fatores associados.

A má oclusão de Classe II, divisão 1 de Angle, caracteriza-se por um relacionamento distal da mandíbula em relação à maxila e/ou do processo alveolar mandibular em relação ao maxilar. Portanto, poder-se-á ter o seu desenvolvimento por uma alteração do relacionamento maxilomandibular, com protrusão maxilar, retrusão mandibular ou ambos (fator esquelético) ou por alteração no relacionamento dentário, quando os dentes inferiores estarão posicionados distalmente aos superiores (fator dentário). Poder-se-á, ainda, observar a combinação desses 2 fatores, situação essa mais comumente encontrada, segundo Henriques et al. ${ }^{29}$

De acordo com Lima Filho, Lima e Ruellas ${ }^{39}$, a morfologia facial é determinada, em grande parte, pelas posições relativas da maxila e da mandíbula, antes, durante e após o pico puberal de crescimento. A posição harmoniosa entre as bases maxilares em relação ao crânio não é responsável somente por uma oclusão funcional, como também por uma estética agradável. Quando as proporções entre maxila e mandíbula estão alteradas entre si ou em relação ao crânio, são observadas deformidades dentofaciais, que podem ocorrer na maxila e/ou mandíbula, nas 3 direções do espaço, mas que freqüentemente ocorrem no plano ântero-posterior, manifestadas na maioria das vezes como má oclusão de Classe II.

\section{Histórico da ancoragem extrabucal}

As modificações dos ossos da face, não só quanto à forma, mas também em relação à direção de deslocamento, são citadas desde meados do século XVIII. Um dos primeiros estudos a respeito do crescimento mandibular foi realizado por Hunter em 1771, concluindo-se que o aumento mandibular resultava da aposição óssea na borda posterior do ramo, promovendo o deslocamento da mandíbula para anterior ${ }^{26}$. Já Humphrey, em 1864, aventou a hipótese de que o crescimento ao nível do ramo mandibular ocorria pela reabsorção da superfície anterior e aposição na superfície posterior, contribuindo para a consolidação da teoria sobre os mecanismos de crescimento por aposição e reabsorção óssea ${ }^{7}$.

A partir destes e de outros estudos pioneiros sobre o crescimento craniofacial, levantou-se a hipótese de interferir nesses mecanismos por meio de recursos mecânicos, como no caso do emprego da ancoragem extrabucal (AEB). O primeiro relato sobre sua utilização remonta há dois séculos quando, em 1802, Cellier utilizou um apoio extrabucal localizado na parte superior e posterior da cabeça, com o objetivo de prevenir a luxação da mandíbula, de forma a imobilizá-1 $a^{44}$. Sua associação na ação direta da maxila ocorreu em 1875 com Kingsley, que conseguiu reduzir uma protrusão maxilar com esse tipo de aparelho, e em 1886 com Farrar, aplicando a força extrabucal diretamente sobre os dentes ântero-superiores ${ }^{44}$. Posteriormente, em 1893, quando Baker introduziu a ancoragem intrabucal intermaxilar por meio de elásticos, seu uso foi relegado por mais de $40 \mathrm{anos}^{44}$. Este fato foi reforçado em 1907, quando Angle, após alguns anos de aplicação clínica do extrabucal, também 
o substituiu pelos elásticos intermaxilares para a correção de Classe II ${ }^{44}$. Mas, em 1936, com Openhein, em Viena, conheceu-se o primeiro relato sobre o tratamento da má oclusão de Classe II, divisão 1 , com ancoragem extrabucal valendo-se de forças leves e intermitentes ${ }^{44}$. Observando o sucesso dessa abordagem, Brodie reintroduziu-a nos Estados Unidos. A partir de então, tornou-se um aparelho difundido e amplamente utilizado para reforço de ancoragem, cada vez mais necessário e reconhecido, graças ao embasamento científico proporcionado pelos estudos de Tweed $^{44}$.

Cresceu, então, o interesse em torno dos efeitos reais induzidos pela ancoragem extrabucal nas estruturas faciais e dentárias. Pelo advento do cefalostato em 1931 ${ }^{7}$, nos EUA com Broadbent e na Alemanha com Hofrath, tornou-se possivel a realização de estudos longitudinais e avaliações do crescimento craniofacial, assim como dos resultados do tratamento ortodôntico instituído ${ }^{7}$. Houve um grande impulso com Broadbent, citado em 1938 em trabalho de Brodie ${ }^{7,8}$, no tangente à divulgação da técnica radiográfica, o que permitiu a Brodie $^{9}$, em 1946, a realização da primeira avaliação cefalométrica de tratamentos ortodônticos finalizados, mostrando que a maioria das mudanças que ocorriam devia-se ao crescimento e ao desenvolvimento, e que os melhores resultados foram obtidos durante a fase de crescimento ativo do paciente (alterações ortopédicas por meio de aplicações ortodônticas). Pôde-se, então, comprovar-se as alterações ósseas e dentárias, contribuindo para que outros trabalhos fossem idealizados avaliando cefalometricamente os efeitos da ancoragem extrabucal.

Kloehn, em 1961, utilizando a região cervical como ponto de apoio, preconizou a indicação desse aparelho como excelente meio de controle para direcionar o crescimento dentoalveolar e, a partir de seus resultados favoráveis, foi o maior divulgador desse recurso ortodôntico ${ }^{15}$. No ano seguinte, Interlandi obteve um melhor controle das forças extrabucais por meio da ancoragem cérvico-occi- pital (IHG), cujo casquete leva seu nome. Graber, durante a década de 70 , relatou que o aparelho extrabucal é de grande importância na correção das más oclusões basais, especialmente no tratamento da má oclusão de Classe II de Angle ${ }^{15}$. Em 1979, Jacobson publicou um artigo corroborando esse relato, visto que, por meio de experimentos mecânicos, demonstrou como as forças extrabucais atuam sobre os dentes e ossos basais, principalmente quando essas forças são assimétricas ${ }^{15}$.

Em 1997, Gandini Jr., Martins e Gandini ${ }^{18}$ realizaram uma avaliação cefalométrica do tratamento da má oclusão de Classe II, divisão 1, por meio do aparelho extrabucal (Kloehn), seguido de aparelhagem fixa, em uma amostra de 45 indivíduos, comparando-a com o grupo controle de 30 pacientes portadores da mesma má oclusão, mas que não foram tratados. As telerradiografias iniciais (T1) e finais (T2) foram comparadas. A média de idade no início do tratamento foi de 10,23 anos para o grupo controle e 11,04 anos para o grupo tratado, sendo o intervalo de análise de 1,35 anos e 3,61 anos, respectivamente. As respostas ao tratamento e as alterações provocadas pelo crescimento foram analisadas e comparadas pelo teste $t$ de Student e U de Man-Whitney. A análise de dados permitiu concluir que o tratamento restringiu, de forma significante, o crescimento para anterior da maxila, expresso pela diminuição da grandeza cefalométrica, menor deslocamento horizontal do ponto A e da espinha nasal anterior. O plano palatino girou no sentido horário, em média, $0,14^{\circ}$ por ano. Notou-se que o deslocamento ânteroposterior das bases ósseas foi melhorado, com significante redução das medidas esqueléticas. A base mandibular não foi significantemente influenciada com o tratamento realizado.

Lima Filho, Lima e Ruellas, em $2003^{39}$, realizaram um estudo longitudinal para avaliar alterações no ANB em pacientes com má oclusão de Classe II esquelética, submetidos ao tratamento com o aparelho extrabucal (Kloehn) no final da dentadura mista ou início da dentadura permanente. 
Utilizaram, para isso, 120 telerradiografias nas fases pré-tratamento, pós-tratamento e pós-contenção. As grandezas cefalométricas foram analisadas para comparação utilizando-se o teste $t$ de Student, obtendo-se, como resultado, que a discrepância maxilomandibular foi corrigida com a utilização do aparelho extrabucal (Kloehn), e que o tratamento foi eficaz na correção da má oclusão de Classe II esquelética, que se manteve estável em longo prazo.

\section{Utilização do arco extrabucal com modificações}

Alguns autores descreveram métodos de conexão do aparelho extrabucal ao aparelho removível. Plint ${ }^{43}$ utilizou o arco facial inserido em tubos soldados às bandas dos molares, sendo o aparelho removível retido por grampos adaptados sobre os tubos dos molares. Cousins e Clark ${ }^{12}$ descreveram um aparelho que incorporava tubos no acrílico, na região palatina dos incisivos superiores, onde o braço interno do arco facial era inserido e, para a sua utilização, realizaram a abertura da mordida o suficiente para permitir que o fio passasse entre os incisivos superiores e inferiores.

Fergusson et al. ${ }^{14}$ idealizaram um aparelho no qual o arco facial era inserido em um tubo soldado a uma alça auxiliar de fio $0,9 \mathrm{~mm}$ sobreposta ao grampo do molar utilizado para retenção do aparelho removível. Segundo esses autores, o risco de irritação aos tecidos e a interferência oclusal constituíam fatores preocupantes na utilização desse tipo de aparelho, devido ao grande volume de acessórios na região dos molares.

Thurow $^{53}$ salientou que o uso do aparelho extrabucal acoplado em bandas nos molares superiores, os quais seriam pontos de aplicação de força, poderia gerar inclinação vestibular ou lingual, dependendo do tipo de tração utilizada, além de seu efeito ser predominantemente dentário, com inclinação distal do $1^{\circ}$ molar. Este autor propôs, então, um aparelho extrabucal acoplado a uma placa de acrílico, com cobertura oclusal de todos os dentes superiores, que ele denominou splint maxilar. $\mathrm{O}$ mesmo autor ${ }^{52}$ referiu-se ao splint maxilar como um arco facial incluído em uma parte de acrílico que recobre os dentes superiores, envolvendo-os por lingual e vestibular. A mecânica desse aparetho assemelha-se à do arco facial convencional, exceto pela força dentária que se distribui sobre todo o arco superior, em vez de atuar somente sobre os molares. O centro de resistência se desloca para anterior, até a região de pré-molares, o que requer modificações dos ajustes no arco externo para obter-se uma aplicação de forças balanceadas. Como a retenção do aparelho depende da manutenção do contato com os dentes por meio de uma força ativa, esse aparelho limita-se à utilização de ângulos elevados de aplicação de forças. Concluiuse que o splint maxilar assemelha-se à ancoragem extrabucal convencional, porém com forças dirigidas para toda a maxila.

Enfatizando o tratamento ortopédico dos problemas esqueléticos durante a fase de crescimento, Henriques, Freitas e Santos-Pinto ${ }^{32}$ apresentaram um caso clínico de correção de uma má oclusão de Classe II, divisão 1 com protrusão maxilar, utilizando o arco facial conjugado a um aparelho removível (AEB conjugado). Os valores cefalométricos obtidos no final do tratamento demonstraram que ocorreu uma redução da velocidade de crescimento maxilar, enquanto outras estruturas do complexo craniofacial mantiveram seu curso normal. A maxila apresentou um aumento de $4,5 \mathrm{~mm}$ em seu comprimento efetivo $(\mathrm{CoA})$, porém em menor proporção do que o comprimento efetivo mandibular (Co-Gn) de $10 \mathrm{~mm}$. O ângulo ANB diminuiu $3^{\circ}$ e o ângulo da convexidade facial (NAP) diminuiu $5,5^{\circ}$. Com o sistema de força extrabucal, obteve-se uma rotação favorável do plano palatino no sentido horário. Portanto a correção da relação molar foi resultado das alterações dentoesqueléticas promovidas pelo AEB conjugado.

Ainda no mesmo ano, Henriques et al. ${ }^{30}$ descreveram os componentes do splint maxilar modi- 
ficado para tratamento da má oclusão de Classe II, divisão 1, assim como as suas funções, ilustrando com um caso clínico, no qual se observava a protrusão maxilar como componente principal da má oclusão. Os autores concluíram que esse aparelho inibe o deslocamento anterior e vertical da maxila e que, embora promova um pequeno controle do movimento dentário individual, é capaz de reduzir ou eliminar a necessidade de uma fase subseqüente de Ortodontia corretiva.

Com o intuito de evidenciar as alterações que podem ocorrer na dentadura mista de pacientes com má oclusão de Classe II, divisão 1 , tratados com ancoragem extrabucal associada a aparelhos removíveis, Henriques, Freitas e Scavone Jr. ${ }^{28}$ relataram um caso clínico em que foi utilizado um aparelho removível na maxila conjugado à ancoragem extrabucal (splint maxilar ou AEB conjugado), a fim de controlar não só o crescimento maxilar como também a distalização do arco dentário superior. Um ano e sete meses após o resultado final, demonstraram a correção da relação molar, da vestibularização dos incisivos, que os comprimentos da maxila e da mandíbula permaneceram inalterados e que o AFAI apresentou sensivel aumento. O ângulo NAP diminuiu e a tendência de crescimento continuou horizontal.

Capelli Jr., Ritter e Cardoso ${ }^{10}$ relataram um caso de tratamento precoce da má oclusão de Classe II, divisão 1 severa, em uma paciente portadora de anemia falciforme, por meio do splint maxilar, o qual conteve a erupção dentária maxilar e o crescimento vertical e anterior da maxila, favorecendo o deslocamento anterior da mandíbula e obtendo o máximo de correção da discrepância maxilomandibular. A segunda fase do tratamento, com aparelhagem fixa, corrigiu o posicionamento dentário e manteve os ganhos esqueléticos da primeira fase.

Santos Pinto et al. ${ }^{45}$ reportaram, por meio de um caso clínico, a utilização de forças extrabucais para o ajuste das relações interdentárias e intermaxilares como um procedimento rotineiro em
Ortodontia, porém apresentando duas importantes variáveis quanto à sua aplicação clínica: direção da aplicação da força e seu ponto de aplicação. Combinações entre tração extrabucal e aparelhos removíveis já foram propostas, como no caso do splint maxilar apresentado por Thurow a partir de 1975. Esse aparelho tem como efeito a restrição do crescimento maxilar, permitindo também a rotação anti-horária da mandíbula.

Costa, Rosa e Pretti ${ }^{11}$ relataram um caso de má oclusão de Classe II, divisão 1, cuja opção de tratamento foi o emprego do splint maxilar de Thurow modificado, que teve como objetivos liberar o crescimento mandibular e controlar o crescimento maxilar, melhorando a relação interarcos, o posicionamento dos incisivos superiores e inferiores, e garantir o controle do crescimento vertical. As conclusões deram-se a partir de uma revisão da literatura e da análise e discussão de um caso clínico que obteve sucesso durante o tratamento.

Almeida et al. ${ }^{1}$ relataram um caso clínico de má oclusão de Classe II, divisão 1, tratado com o aparelho extrabucal conjugado, evidenciando a sua simplicidade de confecção, bem como a relação custo-benefício favorável para o paciente, uma vez que, em muitos casos, não há necessidade da etapa ortodôntica corretiva. Destacaram, ainda, a efetividade de seus resultados sobre o complexo dentoesqueléticofacial na interceptação dessa má oclusão.

Freitas et al. ${ }^{17}$ publicaram um artigo com o objetivo de demonstrar a correção de uma má oclusão de Classe II, divisão 1, na dentadura mista, com padrão de crescimento vertical, maxila protruída e mandibula acentuadamente retruída, com mordida aberta anterior, tendo sido utilizado o AEB conjugado para correção. Como contenção, foi indicado o AEB (IHG) com uma PLA modificada e, após essa fase, o aparelho ortodôntico fixo, dando-se ênfase à obtenção da restrição do crescimento maxilar e à liberação do crescimento mandibular. Concluiu-se que esse tipo de aparelho, quando bem indicado em relação às características 
faciais do paciente e ao seu nível de colaboração, apresenta-se bastante efetivo.

\section{Componentes do AEB conjugado e suas funções}

Nos casos de má oclusão de Classe II, divisão 1, com protrusão maxilar e necessidade de controle vertical, como recurso ortopédico indica-se, atualmente, a utilização do splint maxilar modificado ou AEB conjugado descrito por Henriques et al..$^{30}$, semelhante ao desenvolvido por Thurow na década de 70, o qual apresenta 5 componentes principais: uma placa de acrílico, um parafuso expansor, um arco vestibular, grampos de retenção do tipo Adams e o arco extrabucal.

A placa de acrílico recobre o palato duro e estende-se, lateralmente, até as cúspides vestibulares dos dentes posteriores e, anteriormente, até a face palatina dos incisivos. $\mathrm{O}$ acrílico deve ser o mais fino possível, para evitar translação dos côndilos ou aumento da altura facial inferior. A face de contato com os dentes inferiores não deve interferir no crescimento mandibular.

O parafuso expansor é posicionado na altura do segundo molar decíduo ou segundo pré-molar permanente. Sua ativação permite o ajuste dos segmentos laterais posteriores prevenindo o desenvolvimento de uma mordida cruzada.

$\mathrm{O}$ arco vestibular deve estar em suave contato com os dentes anteriores. Se um incisivo apresenta-se um pouco mais vestibularizado do que os outros, indica-se desgaste do acrílico na região de contato, para que essa inclinação seja normalizada. No entanto, se todos os dentes anteriores estiverem nessa situação, o arco vestibular deve contatálos e o desgaste no acrílico é necessário em toda a extensão anterior.

Os grampos de retenção do tipo Adams devem contornar o primeiro molar permanente auxiliando na estabilização do aparelho e na distribuição de forças através do complexo maxilar, com o maior componente de força direcionado à região dentoalveolar.
O arco extrabucal é colocado no acrílico na área entre os molares decíduos ou pré-molares. Esse dispositivo se estende, posteriormente, até os incisivos laterais e depois curva-se para trás até a borda posterior do primeiro molar permanente. A direção correta, o ponto de aplicação e a quantidade de força aplicada são fatores críticos para o sucesso do tratamento.

\section{Mecanismo de ação e forma de ativação do AEB conjugado}

Qualquer aparelho empregado para restringir o crescimento maxilar anterior e melhorar a relação maxilomandibular deve também restringir a extrusão dos molares permanentes superiores e, conseqüentemente, o deslocamento vertical da maxila. Isso evita a rotação no sentido horário da espinha nasal anterior e dos planos palatino e mandibular.

Para minimizar essa rotação horária, o arco externo deve ser levantado $45^{\circ}$ acima do plano oclusal e usado com tração alta. A aplicação de força nessa direção é voltada para o centro de resistência da maxila, e forças compressivas são distribuídas entre as 3 suturas maxilares primárias: frontomaxilar, zigomaxilar e pterigopalatina. Assim evita-se tensão apenas na sutura frontomaxilar e forças compressivas na sutura pterigopalatina, que são responsáveis pela rotação horária do complexo nasomaxilar. A força aplicada deve ser de 12 a 14 onças (300 a 600 gramas), com elásticos 1/2", trocados a cada 4 ou 5 dias.

Os pacientes tratados com esse aparelho devem ser monitorados até o final do surto de crescimento, embora seja recomendado que o uso do aparelho continue como contenção noturna por um período igual à metade do tempo de duração do tratamento ativo. Nesta fase, os elásticos devem ser trocados a cada 15 dias e, depois, o aparelho deve ser removido gradualmente após esse período.

Segundo Fotis et al. ${ }^{16}$, durante o tratamento com forças ortopédicas sobre a maxila, foi observada uma maior velocidade de crescimento da 
mandíbula em sentido ântero-posterior, podendo o oposto ser notado após o tratamento. Horowitiz e Hixon ${ }^{35}$ afirmaram que essas alterações nas velocidades de crescimento devem-se ao fato de a terapia alterar o curso fisiológico do processo de crescimento e desenvolvimento, podendo até mesmo revertê-lo. Desse modo, após cessada a mecânica, as estruturas tendem a retornar ao seu curso normal de desenvolvimento.

\section{A Ortopedia Funcional dos Maxilares}

Kingsley, em 1879, nos EUA, introduziu o termo e o conceito de aumento da dimensão vertical oclusal (jumping the bite) em curto prazo, para pacientes que apresentavam retrusão mandibular e utilizou um aparelho de vulcanite, que possuía uma inclinação passível de reposicionar a mandíbula anteriormente e guiar a erupção dentária. Essa idéia teve uma influência importante no desenvolvimento das bases da Ortopedia Funcional dos Maxilares ${ }^{6}$.

No entanto, a Ortopedia Funcional dos Maxilares, propriamente dita, teve sua evolução iniciada na França, em 1902, quando Pierre Robin idealizou o monobloco, um aparelho removível que, artificialmente, impunha o avanço postural da mandibula. Esse pesquisador acreditava que o reposicionamento de uma estrutura subdesenvolvida poderia resultar em estímulo para se alcançar o desenvolvimento normal ${ }^{6}$.

Em 1908, o dinamarquês Viggo Andresen, influenciado pelos conceitos de Kingsley, desenvolveu modificações em seu aparelho original de forma a deixá-lo livre dentro da cavidade bucal, tentando, assim, transmitir os estímulos funcionais da musculatura para as bases apicais, os dentes e tecidos de suporte. Postulava-se que o estiramento dos músculos pela protração mandibular resultaria em forças de contração isotônica, as quais seriam transmitidas e distribuídas aos dentes em contato com o aparelho, o que possibilitaria a correção dentoalveolar e ortopédica ${ }^{13}$.

Posteriormente, em 1936, Andresen e Häupl, agora na Noruega, reintroduziram o monobloco de Robin com algumas modificações, passando a denominá-lo ativador ${ }^{13}$. Por seus estudos e aplicações clínicas, concluíram que deveria ser elaborada uma mordida construtiva para registrar o estiramento muscular, assegurando que forças seriam transmitidas do ativador para a maxila e mandíbula. Desde então, muitas alterações adicionais foram incorporadas ${ }^{13,23,28,34}$ por pesquisadores como Balters (1964), Frankel (1969), Bimler (1964) e Clark (1988), dentre outros, originando os mais diversos tipos de aparelhos ortopédicos funcionais ${ }^{19}$.

Curiosamente, observa-se que todos os aparelhos ortopédicos funcionais tiveram origem na Europa ou foram influenciados por preceitos de estudiosos europeus. Esse fato deve-se à coincidência dessa fase da história com o desenrolar das $1^{\mathrm{a}}$ e $2^{\mathrm{a}}$ guerras mundiais, que provocaram escassez de materiais nobres, tendo os ortodontistas, então, sido obrigados a buscarem recursos alternativos para a correção das más oclusões, levando em conta, também, a tendência da época pós-guerra por tratamentos sociais ${ }^{20}$.

\section{Mecanismo de ação dos aparelhos ortopédicos funcionais}

De um modo genérico, os ativadores possuem um corpo único de acrílico, que propicia a alteração da postura da mandíbula em relação à maxila, nos sentidos vertical e horizontal, desencadeando alterações na tonicidade dos músculos peribucais e mastigatórios que favorecem o estabelecimento de adaptações esqueléticas e dentárias, necessárias à correção da má oclusão ${ }^{28}$. O fato de este aparelho permanecer livremente na cavidade bucal, obrigando o paciente a ajustar sua oclusão, originaria energia cinética intermitente. A contração compensatória e o reflexo miostático dos músculos durante os movimentos funcionais forneceriam as forças necessárias para redirecionar o crescimento ou remodelar as bases apicais.

A natureza exata das alterações que contri- 
buem para a correção da má oclusão de Classe II, divisão 1, durante o tratamento com ativador, constitui um tema bastante controverso. Enquanto, por um lado, são admitidas apenas as alterações dentoalveolares, por outro, advoga-se que a terapia induz alterações no padrão de crescimento da maxila e da mandíbula. Contudo, apesar das divergências, estudos clínicos e experimentais avaliando ativadores ou outros aparelhos ortopédicos que propiciem o avanço postural da mandíbula sugerem que a correção da má oclusão de Classe II, divisão 1, decorre dos seguintes fatores:

- remodelação da cavidade glenóide;

- estimulação ou liberação do potencial genético normal de crescimento mandibular;

- redirecionamento ou restrição parcial do crescimento da maxila em direção anterior;

- inclinação e movimentação para distal, ou inibição do processo normal de erupção em direção mesio-oclusal dos dentes póstero-superiores;

- inclinação para lingual dos incisivos superiores;

- inclinação e movimentação para mesial, ou estimulação do processo normal de erupção em direção mesio-oclusal dos dentes póstero-inferiores;

- inclinação para vestibular dos incisivos inferiores.

Segundo Hirzel e Grewe ${ }^{34}$, o tratamento ortopédico consiste em 2 etapas básicas. Na primeira ocorrem alterações dentárias, enquanto na etapa subseqüente desenvolvem-se alterações esqueléticas que, geralmente, requerem um período de tempo mais prolongado.

Martins-Ortiz et $\mathrm{al} .{ }^{40}$, revisando a literatura, concluíram que a cavidade articular (fossa glenóide) possui capacidade adaptativa em variados graus, conforme a intensidade do tratamento ortopédico (intermitente ou contínuo) e da fase de crescimento em que é usado o aparelho. $\mathrm{O}$ deslocamento condilar induzido pela utilização de aparelhos funcionais provoca alterações viscoelásticas nos tecidos moles retrodiscais, provocando, por transdução, a neo-formação óssea na fossa glenóide e no côndilo mandibular. Essa remodelação óssea, intensificada pela utilização do aparelho ortopédico funcional, contribui para a correção das deficiências mandibulares moderadas, principalmente durante o período de utilização dos aparelhos, exigindo sobrecorreção e contenção razoáveis, pela dificuldade de se manter as alterações obtidas, evitando-se a recidiva.

\section{Associação do ativador com as forças extrabucais}

A partir de vários estudos, observa-se que a má oclusão de Classe II, divisão 1 de Angle, freqüentemente apresenta-se com uma combinação da protrusão maxilar e da retrusão mandibular. Quando se encontra esse tipo de situação, ainda durante a fase de desenvolvimento, deve-se pensar em uma abordagem que seja efetiva na restrição do crescimento maxilar e na estimulação do crescimento mandibular.

Procurando alcançar um maior controle sobre o crescimento - assim como sobre o deslocamento anterior e vertical da maxila e o seu processo dentoalveolar durante o tratamento com ativadores passou-se a associá-los com as forças extrabucais aplicadas sobre a maxila. Estas últimas, quando empregadas durante o período de crescimento ativo, podem conduzi-la a um relacionamento mais posterior em relação à base do crânio. Tenenbaum ${ }^{50}$ salienta que a distalização do arco dentário superior com aparelhos removiveis e força extrabucal aplicada na região do molar deve ser efetuada em 2 etapas: primeiramente distalizando-se os setores laterais e posteriores e depois retraindo a região anterior. Esse autor também esclarece que as indicações desses aparelhos são iguais às de outros dispositivos com força extrabucal e que devem ser utilizados, principalmente, durante as horas de sono, até completar 13 horas diárias. Finalmente, evidenciou que o aparelho extrabucal é conectado ao removível e tracionado com elástico cervical.

Deste modo, Pfeiffer e Grobéty ${ }^{42}$ preconizaram 
a associação do ativador com as forças extrabucais de tração cervical aplicadas em tubos soldados nas bandas cimentadas nos primeiros molares superiores. Os autores ressaltaram que os resultados terapêuticos propiciados por essa abordagem representam muito mais do que a simples somatória dos efeitos do ativador e da tração cervical considerados separadamente. Observou-se que o ativador, além de suas propriedades conhecidas, propicia a supressão de quaisquer interferências oclusais que poderiam dificultar o deslocamento para distal da maxila e dos dentes superiores e que, além disso, evita a extrusão excessiva dos primeiros molares superiores. Porém, para os casos de mordida aberta ou com elevada inclinação do plano mandibular, recomenda-se a tração média ou alta.

No entanto, uma série de estudos demonstrou que a tração cervical aplicada aos primeiros molares superiores, freqüentemente, provoca extrusão desses dentes, bem como a rotação para baixo e para trás dos planos palatino e mandibular. Esses efeitos, por sua vez, conduzem ao aumento da altura facial ântero-inferior, além de neutralizarem, parcialmente, o desejado deslocamento anterior do pogônio. Com o intuito de superar ou, ao menos, amenizar esses problemas, Teuscher ${ }^{51}$ desenvolveu um ativador com tubos inseridos bilateralmente no acrílico, na região de pré-molares superiores, que possibilita a inserção direta do arco facial, ao qual aplica-se a tração alta. Essa estratégia, segundo a concepção do autor, possibilita um melhor controle vertical da maxila em função do direcionamento póstero-superior do vetor da força extrabucal aliado à sua maior proximidade do centro de resistência teórico da maxila, situado na região da sutura zigomaxilar.

Quanto à duração do tratamento, Bass ${ }^{5}$ afirmou que a fase ortopédica, normalmente, estendese por 8 a 12 meses, quando se utiliza o ativador combinado às forças extrabucais, muito embora a duração dessa etapa dependa essencialmente da magnitude de crescimento mandibular. Sendo assim, entende-se que a época do surto de cresci- mento puberal representa o momento ideal para a sua indicação. Outro fator intimamente relacionado com o êxito dessa terapia refere-se ao padrão facial do paciente.

Van Beek ${ }^{54}$ também propôs um aparelho único para a correção da má oclusão de Classe II, divisão 1, resultante da combinação do ativador com a ancoragem extrabucal. Os principais aspectos clínicos ante a utilização desse aparelho seriam a intrusão e a retração dos dentes ântero-superiores, a distalização dos molares, a retração maxilar, o estímulo para o crescimento mandibular, a mínima inclinação dos incisivos inferiores e a inibição do deslocamento para baixo da maxila.

Objetivando a efetiva correção da má oclusão de Classe II, divisão 1 , Levin ${ }^{38}$ descreveu um método de tratamento no qual utilizava, simultaneamente, o ativador e a ancoragem extrabucal. Observou-se que essa mecanoterapia resultou em estímulo para o desenvolvimento mandibular normal e redirecionamento do desenvolvimento dentoalveolar superior. Deste modo, obteve-se melhores resultados nos jovens com padrão meso ou braquifacial e notou-se que também parece exercer considerável influência sobre a estabilidade, em longo prazo, da correção ortopédica.

Kingele $^{36}$ concluiu que, após a utilização do ativador associado à ancoragem extrabucal, os resultados foram favoráveis, tanto para os pacientes com crescimento vertical como para os pacientes com crescimento horizontal. A correção da má oclusão de Classe II, divisão 1, ocorreu com a combinação de efeitos dentários e esqueléticos.

Lehmann et al. ${ }^{37}$ indicaram o ativador associado à ancoragem extrabucal para o tratamento da má oclusão de Classe II, divisão 1, com protrusão maxilar e retrusão mandibular durante a fase de crescimento. Relataram, como principais efeitos clínicos, a inibição do crescimento para baixo e para a frente do complexo maxilar e o estímulo ao crescimento mandibular. Esses autores constataram a recidiva parcial da relação molar de Classe II em 17\% dos casos, 5 anos após a conclusão do 
tratamento ortopédico, enquanto nos $83 \%$ restantes a correção manteve-se estável. Os casos que apresentaram recidiva demonstraram, em geral, rotação em sentido horário do "eixo Y" de crescimento facial, avaliado pelo ângulo SN.Gn.

Henriques et al. ${ }^{31}$ publicaram um estudo com o objetivo de avaliar as alterações cefalométricas no tratamento da má oclusão de Classe II, divisão 1 , em pacientes de ambos os gêneros, durante a fase de crescimento e desenvolvimento craniofacial, utilizando o ativador combinado ao aparelho extrabucal (tração média). A amostra constou de 25 pacientes com média de idade de 11 anos. Utilizaram duas telerradiografias em norma lateral de cada paciente, obtidas no início e no final do tratamento, para a comparação das alterações cefalométricas médias, avaliando também a presença de dimorfismo sexual. Concluíram que somente as grandezas SNA, AFAI e 6-PP denotaram dimorfismo sexual. Verificou-se uma restrição de crescimento maxilar, porém sem significância estatística e observou-se um aumento significante no comprimento efetivo da mandíbula, bem como no corpo e na altura do ramo mandibular. Houve uma melhora significante no perfil esquelético e na relação maxilomandibular, embora tenha sido notado um aumento no terço inferior da face. Os incisivos superiores foram verticalizados e retruídos na base óssea, enquanto os molares inferiores apresentaram-se extruídos ao final do tratamento. Houve uma melhora do perfil tegumentar, com retrusão significante do lábio superior.

Henriques et al. ${ }^{23}$ publicaram um trabalho com a proposição de orientar o clínico no planejamento correto da seqüência de tratamento quando anomalias, como as agenesias dentárias, encontramse associadas às más oclusões. Foi apresentado um caso clínico em que 4 pré-molares inferiores e um incisivo inferior estavam ausentes em uma má oclusão de Classe II, divisão 1. Utilizaram um ativador conjugado à ancoragem extrabucal e, ao final do tratamento, o paciente foi encaminhado para a instalação do aparelho fixo e preparo para a posterior colocação de implantes ou próteses nos espaços edêntulos.

Henriques et al. ${ }^{24}$, estudando cefalometricamente os efeitos tegumentares do ativador combinado à ancoragem extrabucal no tratamento da má oclusão de Classe II, divisão 1, observaram que houve inclinação do plano mandibular em relação à base do crânio em virtude do aumento da altura facial ântero-inferior esquelética e tegumentar. Além disso, o posicionamento do lábio superior no sentido ântero-posterior, assim como do lábio inferior e do mento tegumentar, não obtiveram modificações estatisticamente significantes em relação ao grupo controle, embora tenham nitidamente demonstrado maior avanço anterior, com exceção da profundidade do sulco mentolabial, que obteve sensível diminuição com o uso do aparelho.

\section{Componentes, mecanismos de ação e forma de ativação}

Segundo Henriques et al. ${ }^{22}$, o aparelho denominado AEB com ativador apresenta os seguintes componentes: uma estrutura de acrílico superior e uma inferior, unidas na região oclusal; na parte superior, apresenta um parafuso expansor, grampos de retenção tipo Adams, um arco vestibular e um arco facial, incluído no acrílico para receber a tração extrabucal alta. Durante sua construção, a posição da mandíbula deve ser protruída de tal forma que os incisivos adquiram uma posição de topo-a-topo, observando-se, concomitantemente, as relações de normalidade dos caninos e dos primeiros molares permanentes. Essa projeção, medida a partir dos incisivos, não deve ultrapassar $6 \mathrm{~mm}$, podendo ser observada também a região dos primeiros molares permanentes. Nos casos de apinhamento anterior, a relação de topo-a-topo deve ser obtida até a posição do incisivo superior mais lingualizado. Por outro lado, se o avanço necessitar mais de $6 \mathrm{~mm}$ para a obtenção da relação dentária e/ou esquelética favorável, a protrusão mandibular deve ser realizada em etapas progressivas, respeitando-se um intervalo de 8 a 12 meses. A dimensão vertical 
deverá ultrapassar suavemente o espaço funcional livre, para que ocorra o mínimo de estiramento muscular. No entanto, a posição de topo-a-topo dos incisivos promove, normalmente, na região dos primeiros molares permanentes, uma separação de $3 \mathrm{~mm}$ a $4 \mathrm{~mm}$, suficiente, portanto, para liberar um sistema de forças musculares capazes de instituírem modificações esqueléticas satisfatórias.

A placa de acrílico maxilar recobre, parcialmente, o palato duro e as superfícies oclusais dos dentes póstero-superiores. Na parte superior do aparelho adaptam-se os grampos de Adams, o arco vestibular, o arco facial e o parafuso expansor. Os grampos de Adams são confeccionados com fio $0,7 \mathrm{~mm}$ na região de primeiros molares permanentes, para auxiliar na retenção do aparelho. $\mathrm{O}$ arco vestibular, também de fio $0,7 \mathrm{~mm}$, estende-se de distal a distal de caninos, objetivando, além de retenção, uma tração da maxila com maior efeito ortopédico ou a possibilidade de ativá-lo também no caso dos incisivos encontrarem-se vestibularizados. $\mathrm{O}$ arco facial é confeccionado com fio $1,5 \mathrm{~mm}$ de diâmetro e, neste caso especificamente, seus braços internos são inseridos diretamente no acrílico na região de prémolares permanentes ou molares decíduos. Porém, em alguns casos, pode-se posicioná-lo na região de primeiros molares permanentes ou caninos. Os braços externos prolongam-se até a face distal dos primeiros molares permanentes. $\mathrm{O}$ parafuso expansor será posicionado de forma centralizada na altura dos molares decíduos ou pré-molares, evitando o desenvolvimento de uma mordida cruzada posterior durante a terapia.

Os elásticos 1/2", trocados em média a cada 3 a 4 dias, fornecem uma força extrabucal em torno de 350 gramas a 600 gramas e devem exercer tração em direção superior ou intermediária preferencialmente. Esse procedimento, em associação ao ponto de inserção dos arcos faciais no acrílico, ajuda a prevenir a extrusão dos primeiros molares superiores e a rotação do plano palatino em sentido horário.

Formando um corpo único com a placa maxi- lar, o componente mandibular recobre as superfícies oclusais dos dentes póstero-inferiores. Normalmente as bordas incisais dos incisivos inferiores também são recobertas para evitar ou, ao menos, minimizar a tendência de vestibularização durante a terapia. O componente mandibular também possui extensões de acrilico recobrindo as superficies linguais dos dentes inferiores e parte do processo alveolar. Essas extensões linguais em associação ao recobrimento das superfícies oclusais dos dentes póstero-superiores e inferiores guiarão a mandíbula à posição desejada nos sentidos ânteroposterior e vertical.

Em geral, a ativação ântero-posterior corresponde à obtenção de um relacionamento de topoa-topo entre os incisivos, na forma preconizada por Harvold e Vargervick ${ }^{21}$. A ativação vertical depende da espessura do acrílico interposto entre os dentes posteriores, que normalmente deve representar apenas o espaço suficiente para eliminar a sobremordida e permitir o relacionamento de topo-a-topo entre os incisivos.

Quanto à utilização diária do aparelho, os pacientes são orientados a retirá-lo apenas durante as refeições, na higienização bucal e prática de esportes. Caso o paciente esteja utilizando adequadamente o aparelho e apresente potencial de crescimento favorável, após um período médio de 3 meses, já se observa uma sensível melhora na relação entre os arcos dentários. No entanto, esse episódio decorre de adaptações dentárias e musculares. Por esta razão, a utilização do aparelho não deve ser interrompida e nem reduzida nesse momento, pois as alterações esqueléticas requerem um período de tempo mais prolongado.

\section{Comparação entre diferentes tipos de tratamento}

A avaliação cefalométrica das estruturas dentoesqueléticas em pacientes com má oclusão de Classe II, divisão 1 de Angle, comparando-se os tratamentos realizados com 2 tipos de ancoragem extrabucal (cervical e associada ao aparelho remo- 
vível) foi realizada por Henriques, Freitas e Pin$z^{25}{ }^{25}$. A amostra constou de telerradiografias em norma lateral de 50 jovens, de ambos os gêneros, com média de idade de 10 anos, divididos em 2 grupos: tratados com ancoragem extrabucal cervical e tratados com aparelho removível conjugado à ancoragem extrabucal. Quanto à influência do tratamento, os autores concluíram que:

- não ocorreram alterações no padrão de crescimento nos 2 grupos;

- a maxila mostrou restrição de crescimento e a mandíbula apresentou discreto crescimento nos 2 grupos,

- o ângulo nasolabial (ANL) não foi alterado significativamente, porém o de convexidade (NAP) mostrou-se significantemente diminuído;

- os incisivos superiores apresentaram uma verticalização significante, enquanto os incisivos inferiores não tiveram grandes alterações de suas posições originais;

- os molares superiores distalizaram nos 2 grupos, embora no grupo da ancoragem cervical tenha sido observada extrusão.

Quanto ao dimorfismo sexual:

- não ocorreram diferenças significantes nos 2 grupos para as seguintes medidas: SNA, SNB, ANB, NAP, ANL, SN.PP, A-Nperp, A-Sperp, BSperp, 1.PP, IMPA, 6-GoMe, 6-Sperp e 6'-Sperp;

- apresentaram diferenças significantes: AFAI, SnGoMe e 6-PP.

No mesmo ano, esses mesmos autores ${ }^{26}$ publicaram um estudo cefalométrico comparativo dos tratamentos da má oclusão de Classe II, divisão 1 , realizados com ancoragem extrabucal cervical e AEB associado ao ativador. A amostra constou de radiografias de 50 pacientes, de ambos os gêneros, idade média de 10 anos, divididos em 2 grupos: tratados com AEB cervical e tratados com o ativador associado ao AEB. Quanto à influência do tratamento, concluíram que:

- não ocorreram alterações no padrão de crescimento;

- a maxila mostrou restrição de crescimento em ambos os grupos, e o ângulo do plano palatino aumentou significantemente no primeiro grupo;

- a mandíbula apresentou crescimento significante no segundo grupo, sendo este crescimento mais discreto no primeiro grupo;

- o ângulo nasolabial (ANL) não foi significantemente alterado, enquanto o de convexidade (NAP) mostrou-se diminuído nos 2 grupos;

- os incisivos superiores mostraram-se verticalizados, enquanto os inferiores não alteraram significativamente suas posições originais nos 2 grupos;

- os molares superiores distalizaram nos 2 grupos, embora os do grupo 1 tenham apresentado extrusão. Os molares inferiores apresentaram uma extrusão significante no segundo grupo.

Quanto ao dimorfismo sexual:

- não ocorreram diferenças significantes nos 2 grupos para as seguintes medidas: SNA, SNB, ANB, NAP, ANL, SN.PP, A-Nperp, A-Sperp, BSperp, 1.PP, IMPA, 6-GoMe, 6-Sperp e 6'-Sperp;

- apresentaram diferenças significantes: AFAI, SnGoMe e 6-PP.

Henriques, Freitas e Pinzan ${ }^{27}$ avaliaram cefalometricamente 50 pacientes com má oclusão de Classe II, divisão 1, subdivididos em 2 grupos: o primeiro tratado com AEB associado ao aparelho removivel e o segundo tratado com AEB associado ao ativador. Quanto à influência do tratamento concluíram que:

- não ocorreram alterações no padrão de crescimento;

- a maxila mostrou restrição de crescimento em ambos os grupos;

- a mandíbula apresentou crescimento significante no segundo grupo, sendo este crescimento mais discreto no primeiro grupo;

- o ângulo nasolabial (ANL) não foi significantemente alterado, enquanto o de convexidade (NAP) mostrou-se diminuído nos 2 grupos;

- os incisivos superiores mostraram-se verticalizados, enquanto os inferiores não alteraram significativamente suas posições originais nos 2 grupos; 
- os molares superiores distalizaram nos 2 grupos, embora os do grupo 1 tenham apresentado estabilidade cervico-oclusal, tendo ocorrido intrusão não significante no grupo 2. Os molares inferiores extruíram nos grupos 1 e 2 , principalmente neste último.

Quanto ao dimorfismo sexual:

- não ocorreram diferenças significantes nos 2 grupos para as seguintes medidas: SNA, SNB, ANB, NAP, ANL, SN.PP, A-Nperp, A-Sperp, BSperp, 1.PP, IMPA, 6-GoMe, 6-Sperp e 6'-Sperp;

- apresentaram diferenças significantes: AFAI, SnGoMe e 6-PP.

Cruz et al. ${ }^{13}$ realizaram uma revisão da literatura sobre 5 tipos de aparelhos funcionais para a correção da má oclusão de Classe II: o ativador, o bionator de Balters, o regulador de função de Frankel, o aparelho de Herbst e os guias de erupção. De um modo geral, constatou-se que esses aparelhos devem ser utilizados por pacientes na fase de crescimento ativo, visando corrigir discrepâncias ântero-posteriores, verticais e transversais pela restrição e/ou redirecionamento do crescimento das bases apicais. $\mathrm{O}$ ativador e o Bionator apresentam o mesmo mecanismo de ação, promovendo alterações dentoesqueléticas similares. Verificou-se que esses aparelhos promovem uma melhora do perfil facial, com a coordenação do crescimento maxilomandibular, reduzindo, na maioria das vezes, a necessidade de extrações. Dessa forma, ocorre uma diminuição da fase com aparelhos fixos, podendose até mesmo eliminá-la.

Santos e Henriques ${ }^{46}$ realizaram um estudo cefalométrico comparativo de duas formas distintas de tratamento da má oclusão de Classe II, divisão 1. Cada grupo contou com 25 integrantes de ambos os gêneros, com potencial de crescimento craniofacial, tendo o primeiro sido tratado com aparelhagem fixa e técnica Edgewise e o segundo grupo tratado, inicialmente, com o ativador combinado com a ancoragem extrabucal occipital e finalizado com aparelhagem fixa e técnica Edgewise. Não houve diferenças significantes entre as alterações médias da maxila, mandíbula, relação maxilomandibular e padrão de crescimento facial. Nos pacientes do grupo 2, observou-se maior protrusão e vestibularização dos incisivos inferiores, com significância estatística ao nível de 5\%. A única grandeza avaliada que apresentou diferença estatisticamente significante foi Gl'Sn'-Pog. A indicação de aparelhos funcionais em fase inicial de tratamento da má oclusão de Classe II, divisão 1, com deficiência mandibular, durante o desenvolvimento craniofacial e complementação com aparelhagem fixa apresenta-se favorável.

\section{CONCLUSÃO}

A efetividade dos recursos ortopédicos descritos - AEB conjugado e AEB com ativador - está diretamente relacionada com a seleção diagnóstica criteriosa e o grau de interesse e colaboração do paciente, salientando-se o controle vertical. As avaliações das alterações cefalométricas e de perfil tegumentar induzidas por esses aparelhos mostraram-se satisfatórias, com efeitos ortodônticos e ortopédicos significantes, o que promove uma melhora da discrepância esquelética proporcionada, principalmente, pelo redirecionamento do crescimento. Se faz relevante salientar a importância da fase de contenção para a manutenção dos resultados alcançados, embora estes mostrem-se consistentes em longo prazo. 


\title{
Class II, division 1, with maxillar protrusion's treatment employing orthopedic approachs
}

\begin{abstract}
Aim: The purpose of this research is to review the literature about the treatment of Class II, division 1 malocclusion with maxillary protrusion, during the growth and development period. This review addresses the characteristics of these appliances, their components, correct use, action mechanisms, and mainly their consequences in dentofacial complex. Conclusions: In patients with maxillary protrusion and with no mandibular component, it may be indicated the use of a maxillary splint similar to the one suggested by Thurow. However, in patients with maxillary protrusion and mandibular retrusion, it may be indicated an activator associated with extra oral anchorage.
\end{abstract}

Key words: Class II. Division 1. Orthopaedic. Maxilar protrusion.

\section{REFERÊNCIAS}

1. ALMEIDA, R R : ALMEIDA, M R : BRANGELI, A M MALTAGLIATI, A. M. A.; PEDRIN, R. R. A.; HENRIQUES, J. F. C. Utilização do AEB conjugado na interceptação da má oclusão de Classe II divisão1. Rev. Assoc. Paul. Cir. Dent., São Paulo, v. 56 , no. 4 , p. 308-311, 2002.

2. ANDERSON, G. M. On the diagnosis and treatment of distocclusion. Am. J. Orthod., St. Louis, v. 32, no. 1, p. 88-94, 1946.

3. ANGLE, E. H. Malocclusions of the teeth. 7th ed. Philadelphia: S. S. White, 1907.

4. BASS, N. M. Dentofacial orthopedics in the correction of Class II malocclusion. Br. J. Orthod., Oxford, v. 9, p. 3-31, 1982.

5. BASS, N. M. Orthopedic coordination of dentofacial development in skeletal Class II malocclusion in conjunction with edgewise therapy. Part I. Am. J. Orthod., St. Louis, v. 84, no. 5, p. 361-383, 1983

6. BISHARA, S. E.; ZIAJA, R. R. Functional appliance: a review. Am. J. Orthod., St. Louis, v. 95, no. 3, p. 250-258, 1989.

7. BRODIE, A. G. The Angle concept of Class II, division 1 malocclusion. Angle Orthod., Appleton, v. 1, no. 2, p. 117-138, 1931.

8. BRODIE, A. G. Cephalometric appraisal of orthodontic results. Angle Orthod., Appleton, v. 8, no. 4, p. 261-265, 1938.

9. BRODIE, A. G. Facial patterns: a theme of variation. Angle Orthod., Appleton, v. 16, no. 3, p. 75-87, 1946.

10. CAPELLI JUNIOR, J.; RITTER, D. E.; CARDOSO, M. G. Tratamento da Classe II severa em paciente portador de anemia falciforme. Rev. Brás. Odontol., Rio de Janeiro, v. 56, n. 6, p. 260-263, 1999

11. COSTA, L. B. M.; ROSA, R. T. F.; PRETTI, H. Tratamento da Classe II divisão 1 com splint maxilar de Thurow modificado: relato de caso. J. Bras. Ortodon. Ortop. Facial, Curitiba, v. 7, n. 37, p. 64-169, 2002

12. COUSINS, A. J. P.; CLARK, W. J. Extra-oral traction theorical considerations and the development of a removable appliance technique. Trans. Br. Soc. Study Orthod., Bristol, p. 37-44, 1995.

13. CRUZ, K. S.; HENRIQUES, J. F. C.; DAINESI, E. A.; JANSON, G. R. P. Efeitos dos aparelhos funcionais na correção da má oclusão de Classe II. Rev. Dental Press Ortodon. Ortop. Facial, Maringá, v. 5, n. 4, p. 43-52, 2000

14. FERGUSSON, J. W. et al. A new method of attaching headgear to upper removable appliances. Br. J. Orthod., Oxford, v. 10, p. $48-49,1983$
15. FERREIRA, F. V. Ortodontia: diagnóstico e planejamento. 4. ed. São Paulo: Artes Médicas, 1993.

16. FOTIS, V.; MELSEN, B.; WILLIAMS, S.; DROSCHL, H. Vertical control as an important ingredient in treatment of severe sagital discrepancies. Am. J. Orthod., St. Louis, v. 86, p. 224-232, 1984

17. FREITAS, M. R.; BELTRÃO, R. T. S.; FREITAS, K. M. S.; VILLAS BOAS, J.; HENRIQUES, J. F. C. JANSON, G. R. P. Um tratamento simplificado para correção da má oclusão de Classe II, divisão $1 \mathrm{com}$ mordida aberta: relato de um caso clínico. Rev. Dental Press Ortodon. Ortop. Facial, Maringá, v. 8, n. 3, p. 93-100, 2003

18. GANDINI JÚNIOR, L. G.; MARTINS, J. C. R.; GANDINI, M. R. E. A. S. Avaliação cefalométrica do tratamento da Classe II divisão $1 \mathrm{com}$ o aparelho extrabucal Kloehn e com aparelho fixo: alterações esqueléticas: Parte I. Rev. Dental Press Ortodon. Ortop. Facial, Maringá, v. 2, n. 6, p. 75-87, 1997.

19. GRABER, T. M.; NEUMAN, B. Aparelhos funcionais. In: Ortodontia: princípios e técnicas atuais. 2. ed. Rio de Janeiro: Ed. Guanabara, 1985. cap. 8, p. 349-399.

20. GRABER, T. M.; NEUMAN, B. Aparelhos ortodônticos removíveis. 2. ed. São Paulo: Panamericana, 1987.

21. HARVOLD, E. P.; VARGERVICK, K. S. Morphogenetic response to activator treatment. Am. J. Orthod., St. Louis, v. 60, p. 478-490, 1971.

22. HENRIQUES, J. C. H.; ALMEIDA, R. R.; FREITAS, M. R.; CUOGHI, O. A.; SANTOS, E. C. A. Ativador combinado com a ancoragem extrabucal: considerações sobre a sua construção. Ortodontia, São Paulo, v. 25, n. 3, p. 67-72, 1992.

23. HENRIQUES, J. F. C.; BRANGELI, L. A. M.; FREITAS, M. R.; JANSON, G. R. P. Correção de uma Classe II, divisão 1, com anodontia inferior dos pré-molares e de um incisivo, utilizando ativador combinado ao aparelho extrabucal. Ortodontia, São Paulo, v. 32, n. 3, p. 72-81, 1999.

24. HENRIQUES, J. F. C.; BRANGELI, L. A. M.; FREITAS, M. R.; JANSON, G. R. P. Estudo comparativo dos efeitos tegumentares do ativador combinado com a ancoragem extrabucal no tratamento da Classe II, divisão 1 de Angle. Rev. Dental Press Ortodon. Ortop. Facial., Maringá, v. 7, n. 4, p. 15-22, 2002.

25. HENRIQUES, J. F. C.; FREITAS, M. R.; PINZAN, A Estudo cefalométrico comparativo de dois tipos de ancoragem extrabucal (cervical e associada ao aparelho removível), em pacientes Classe II, divisão1. Ortodontia, São Paulo, v. 28, n. 2, p. 4-13, 1995 
26. HENRIQUES, J. F. C.; FREITAS, M. R.: PINZAN, A. Estudo cefalométrico comparativo de dois tipos de ancoragem extrabucal: cervical e associada ao ativador, em pacientes Classe II, divisão1. Ortodontia, São Paulo, v. 28, n. 3, p. 20-30, 1995.

27. HENRIQUES, J. F. C.; FREITAS, M. R.; PINZAN, A. Estudo cefalométrico comparativo de dois tipos de ancoragem extrabucal (associada ao ativador e ao aparelho removível), em pacientes Classe II, divisão1. Ortodontia, São Paulo, v. 29, n. 2, p. 45-62 1996.

28. HENRIQUES, J. F. C.; FREITAS, M. R.; SCAVONE JUNIOR, H. $O$ ativador conjugado ao aparelho extrabucal, durante o tratamento ortopédico-ortodôntico: descrição do aparelho e relato de um caso clínico. Ortodontia, São Paulo, v. 26, n. 1, p. 106-116, 1993

29. HENRIQUES, J. F. C.; MALTAGLIATI, L. A.; FREITAS, M. R.; JANSON, G. R. P. MALTAGLIATI, A. M. A Utilização do aparelho removível conjugado à ancoragem extrabucal no tratamento da Classe II, divisão 1 com sobremordida profunda. Rev. Dental Press Ortodon. Ortop. Facial., Maringá, v. 2, n. 2, p. 12-18, 1997

30. HENRIQUES, J. F. C.; MARTINS, D. R.; ALMEIDA, G. A.; URSI, W. J. S. Modified maxillary splint for Class II, Division 1 treatment. J. Clin. Orthod., Boulder, v. 15, no. 4, p. 239-245, 1991.

31. HENRIQUES, J. F. C.; ALMEIDA, M. C.; ALMEIDA, R. R.; SANTOS, E. C. A. Avaliação cefalométrica dos efeitos do ativador combinado à ancoragem extrabucal (tração média) em jovens com má oclusão de Classe II, divisão 1 de Angle. Rev. Dental Press Ortodon. Ortop. Facial, Maringá, v. 2, n. 5, p. 77-90, 1997.

32. HENRIQUES, J. F. C.; FREITAS, M. R.; SANTOS-PINTO, C. C. M. Correção de uma má oclusão de Classe II, divisão 1, com protrusão maxilar, utilizando o arco facial conjugado a um aparelho removível (AEB conjugado). Ortodontia, São Paulo, v. 24, n. 3, p. 14-18, 1991.

33. HENRY, R. G. A classification of Class II, division 1 malocclusion. Angle Orthod., Appleton, v. 27, no. 2, p. 83-92, 1957.

34. HIRZEL, H. C.; GREWE, J. M. Activators: a practical approach Am. J. Orthod., St. Louis, v. 66, no. 5, p. 557-570, 1974

35. HOROWITIZ, S. L.; HIXON, E. H. Physiologic recovery following orthodontic treatment. Am. J. Orthod., St. Louis, v. 55, no. 1, p. 1-4, 1969.

36. KINGELE, E. Cephalometric changes from activator headgear treatment of Class II, division 1 maloclusion. J. Clin. Orthod. Boulder, v. 21, no. 27, p. 466-469, 1987.

37. LEHMANN, R. et al. Five years treatment results with a headgear activator combination. Eur. J. Orthod., Oxford, v. 10, p. 309-318, 1988

38. LEVIN, R. I. Activator headgear therapy. Am. J. Orthod., St. Louis, v. 87, no. 2, p. 91-109, 1985

39. LIMA FILHO, R. M. A.; LIMA, A. L.; RUELLAS, A. C. O. Estudo longitudinal das alterações no ângulo ANB em pacientes Classe II esquelética, tratados com aparelho extrabucal de Klohen. Rev. Dental Press Ortodon. Ortop. Facial, Maringá, v. 8, n. 2, p. 21-29, 2003.

40. MARTINS-ORTIZ, M. F.; JANSON, G.; PINHEIRO, F. L. S. MARTINS, D. R. Alterações microscópicas da cavidade glenóide induzidas pelo uso de aparelhos funcionais. Rev. Dental Press Ortodon. Ortop. Facial., Maringá, v. 6, n. 5, p. $125-132,2001$.

41. MOYERS, R. E. Ortodontia. 4. ed. Rio de Janeiro: Guanabara Koogan, 1991.

42. PFEIFFER, J. P.; GROBÉTY, D. Simultaneous use of cervical appliance and activator: an orthopedic approach to fixed appliance therapy. Am. J. Orthod., St. Louis, v. 61, no. 4 p. 353-373, 1972.

43. PLINT, D. A. A method of treatment Class II, div. 1 cases with out using the lower arch for anchorage of traction. Trans. Br. Soc. Study Orthod., Bristol, p. 49-55, 1961.

44. PROFFIT, W. R. Ortodontia contemporânea. 2. ed. Rio de Janeiro: Guanabara Koogan, 1993.
45. SANTOS PINTO, A.; MARTINS, L. P.: MELO, A. C. M.: PAULIN, R. F.; OSHIRO, L. O aparelho extrabucal de Thurow modificado no tratamento da Classe II com mordida aberta: caso clínico. Rev. Dental Press Ortodon. Ortop. Facial, Maringá, v. 6, n.1, p. 57-62, 2001.

46. SANTOS, E. C. A.; HENRIQUES, J. F. C. Estudo cefalométrico entre as alterações resultantes de dois tipos de tratamento da má oclusão de Classe II, $1^{\text {a }}$ divisão de Angle. Rev. Dental Press Ortodon. Ortop. Facial, Maringá, v. 5, n. 6, p. 11-31 2000.

47. SASSOUNI, V. A. A classification of Class II, division 1 maloclusion. Am. J. Orthod., St. Louis, v. 55, p. 109-123, 1969.

48. SCHUDY, F. F. Vertical growth versus anteroposterior growth as related to function and treatment. Angle Orthod., Appleton, v. 34, p. 75-93, 1964

49. SILVA FILHO, O. G.; FREITAS, S. E.; CAVASSAN, A. O. A prevalência da oclusão normal e má oclusão em escolares da cidade de Bauru (São Paulo). Parte II: influência da estratificação sócio-econômica. Rev. Odontol. Univ. São Paulo, São Paulo, v. 4, n. 3, p. 189-196, 1990

50. TENENBAUM, M. Fuerza extraoral com aparatos fijos e removibles. Buenos Aires: Mundi, 1969

51. TEUSCHER, U. A growth-related concept for skeletal Class II treatment. Am. J. Orthod., St. Louis, v. 74, no. 3, p. 258-275, 1978.

52. THUROW, R. C. Atlas de princípios ortodônticos. Buenos Aires: Inter Médica, 1979.

53. THUROW, R. C. Craniomaxillary orthopedic correction with en masse dental control. Am. J. Orthod., St. Louis, v. 68, p. 601-624, 1975

54. VAN BEEK, H. Combination headgear - activator. J. Clin. Orthod., Boulder, v. 18, no. 3, p. 185-198, 1984.
Endereço para correspondência

Carla Maria Melleiro Gimenez

R. Padre Duarte, 989, apto 24 - Centro

CEP: 14.801-310 - Araraquara/SP

E-mail: carlamg@yahoo.com 